Fifth International Conference on Sustainable Construction Materials and

Technologies. http://www.claisse.info/Proceedings.htm

\title{
SUSTAINABILITY PATTERNS AND TRADEOFFS THROUGH A GRAPHICAL SUSTAINABILITY INDEX
}

\author{
Rita Awwad ${ }^{1}$ and Karim El Khoury ${ }^{2}$
}

\author{
${ }^{1}$ Associate Professor, Civil Engineering Department, Lebanese American University, \\ P.O.Box 36, Byblos, Lebanon, email: rita.awwad@lau.edu.lb. \\ ${ }^{2}$ Former Undergraduate Student, Civil Engineering Department, Lebanese American \\ University, P.O. Box 36, Byblos, Lebanon, email: karimk@jkdevelop.com.
}

\begin{abstract}
Sustainable construction has been receiving growing attention around the world. However, the desire to chase sustainable rating systems often stems from a company's competitive marketing edge and revenue boosting goals, which is reflected through the selection of easily applicable sustainability features at the least cost. This research addresses the question of whether sustainability is perceived as a marketing tool or a serious environmental commitment through developing a comprehensive graphical sustainability index that combines all criteria adopted in commonly used rating systems under four categories (social, economic, environmental, and practice) in a simplified graphical format. The developed index is used to assess some sustainable projects in the Lebanese market in order to identify its particular sustainability patterns and tradeoffs. Findings show that satisfying the practice, social and environmental pillars comes at the expense of the economic dimension, which affirms that the perception of higher costs associated with sustainable construction still prevails.
\end{abstract}

Keywords: Sustainable construction; graphical sustainability index; Lebanon; sustainability tradeoffs; economic constraint.

\section{INTRODUCTION}

The construction sector is among the most influential industries that could greatly contribute to a country's sustainable development. Several studies focused on the positive impact an eco-friendly building can have on the environment, the economy and the society at large (Holton et al.,2007; Sev, 2009; Pitt et al,. 2009; Said et al 2010). 
Developed countries have reached a higher awareness level and consequently a more serious commitment to sustainable construction than developing countries (Awwad and El Khoury, 2012). For instance, green buildings are becoming a lifestyle choice rather than just a trend in the American society (Robichaud and Anantatmula 2011). Developing countries are yet far from reaching this level of maturity due to their particular development challenges, lack of the industry capacity and required skills, scarcity of resources, political conflicts, cultural habits and others (CIB and UNEP 2002). Lebanon, a small developing country in the Middle East region, is witnessing a construction boom after a series of wars that damaged the country's infrastructure, weakened its economy, depleted its natural resources and greatly polluted its environment. In the absence of any national waste management plan and with very limited recycling options, the majority of debris accumulated from wars was dumped at temporary sites which poses a threat to the ecosystem and the hydrogeology (Srour et al. 2010). On the other hand, Lebanon has lost about $75 \%$ of its limited forest and woodland resources from 1968 to 1991 due to unplanned development and construction and the situation kept worsening afterward (World Bank 2003, El Asmar and Taki 2014). These facts highlight the urgent need for a major transition from a shortsighted construction focusing on short-term goals of profit-making and fast growth and lacking concern for the environment to a global long-term sustainable development that ensures the welfare of current and future generations. However, the perception of higher costs and lost profit associated with sustainable construction by developers and contractors remains the most commonly cited obstacle to implementing sustainable practices (McGraw-Hill Construction, 2006). Hence, sustainability is still seen as a luxury in developing countries such as Lebanon and is rather used by developers as an advertising tool that gives them an edge over other competitors in the market.

In light of the aforementioned, this paper aims at developing a comprehensive graphical sustainability index that highlights four main pillars of sustainability, namely practice, environmental, social and economic and that is intended to be used to identify the most common sustainability patterns implemented on site and trade-offs among sustainability pillars for any construction sector. This index is used to highlight adopted sustainability features in the Lebanese market and to devise recommendations to enhance sustainable development and awareness in Lebanon which may be of insight to other developing countries as well.

\section{BACKGROUND}

Several multi-criterion systems have been developed all over the world to assess the sustainability features of buildings. The British Building Research Establishment Environmental Assessment Method (BREEAM) is the oldest assessment system which was launched in the United Kingdom in 1990 and became widely adopted internationally in few years. The Leadership in Energy and Environmental Design (LEED) building assessment system created by the US Green Building Council (USGBC) in 1998 is also one of the most popular sustainability rating systems around the world expanding over more than 140 countries and regions (Kibert 2016). Other 
famous sustainability assessment tools that rank second to the two aforementioned systems include the Comprehensive Assessment System for Building Environmental Efficiency (CASBEE) developed by the Japan Sustainable Building Consortium, Green Globes developed by ECD Energy and Environment Canada and used primarily in Canada and the United States, the Australian Building Greenhouse Rating (ABGR), the Chinese Three Star, the US Assessment and Rating System (STARS), the German assessment tool by the German Sustainable Building Council (DGNB), the South African Sustainable Building Assessment Tool (SBAT) and others. These systems have common evaluation features and are mainly characterized by their additional structure where each criterion is assigned a number of points that are granted to the assessed building depending on how many parameters are satisfied within this criterion. Accordingly, the higher the number of sustainability points accumulated by the evaluated building, the higher is the granted certification level.

The aforementioned systems have been criticized for being too focused on the environmental dimension leaving out other aspects which are of equal importance such as social and economic considerations (Sev 2009; Hugé et al. 2013). Until these days, reduction in energy consumption and GHG emissions remains to receive the highest weight among other categories in all building assessment tools lacking concern for the financial impacts of such sustainable measures especially in developing countries with unstable economies (Berardi 2012; Gibberd 2005). Sustainable buildings result in longterm economic advantages to their tenants through cost savings in energy, water, operation and maintenance; however the situation is not the same for developers who have to bear the high cost premium of going green during the building construction phase. Therefore, developers either refrain from delivering sustainable buildings or tend to game the adopted sustainability rating system by achieving the minimum number of easy points required to meet the targeted certification level (King and Toffel 2007). For instance, the LEED system indicates that including an easy to implement feature such as a bike rack in a building is awarded one point whereas a much costlier criterion such as the redevelopment of a brownfield is also worth a point. This implies that at each decision to implement a sustainability criterion designated by a certain rating system on a given building, tradeoffs between ecological and economic concerns are being made by developers to achieve the minimum targeted certification level at the least cost (King and Toffel 2007). As a result, integrating the three primary dimensions (social, economic and environmental) which are at the core of sustainable development is not being implemented properly where tradeoffs seem to be inexorable in practice. This has culminated in two mutually exclusive concepts of "weak" versus "strong" sustainability where the former emphasizes the economic dimension and the latter is more focused on the environmental considerations (Hediger 1999).

\section{METHODOLOGY}

This study developed a graphical sustainability index that helps provide insight to green consultants, policy makers and initiators in this field into sustainable development trends and tradeoffs, as well as highlight weaknesses and potential improvements to reach a well-balanced sustainable performance. Then, this index was used to 
investigate the level of commitment of Lebanese construction developers to sustainable practices by surveying four completed projects of which one is BREEAM certified at an excellent rating and is the only BREEAM registered project in Lebanon, and three are LEED certified at the gold level.

\section{Questionnaire Design}

Semi-structured interviews have been conducted with developers, consultants, architects, and project managers who were involved in the surveyed projects in order to identify sustainability patterns and tradeoffs that characterize the Lebanese construction sector and highlight its weak or strong sustainable performance. For this purpose, this study reviewed the most commonly used sustainability rating systems worldwide and designed a questionnaire that consisted of two sections. The first section compiled the different assessed criteria under the two most famous rating systems, LEED and BREEAM, and classified them into four main categories (Practice, Environmental, Social, Economic) in order to emphasize practices and tradeoffs between the distinct sustainability pillars in a certain construction industry. Each category comprised multiple subcategories which in turn were assessed based on several criteria as shown in Error! Reference source not found.. Interviewees were asked to indicate the different measures they have taken, if any, to satisfy each of the listed criteria.
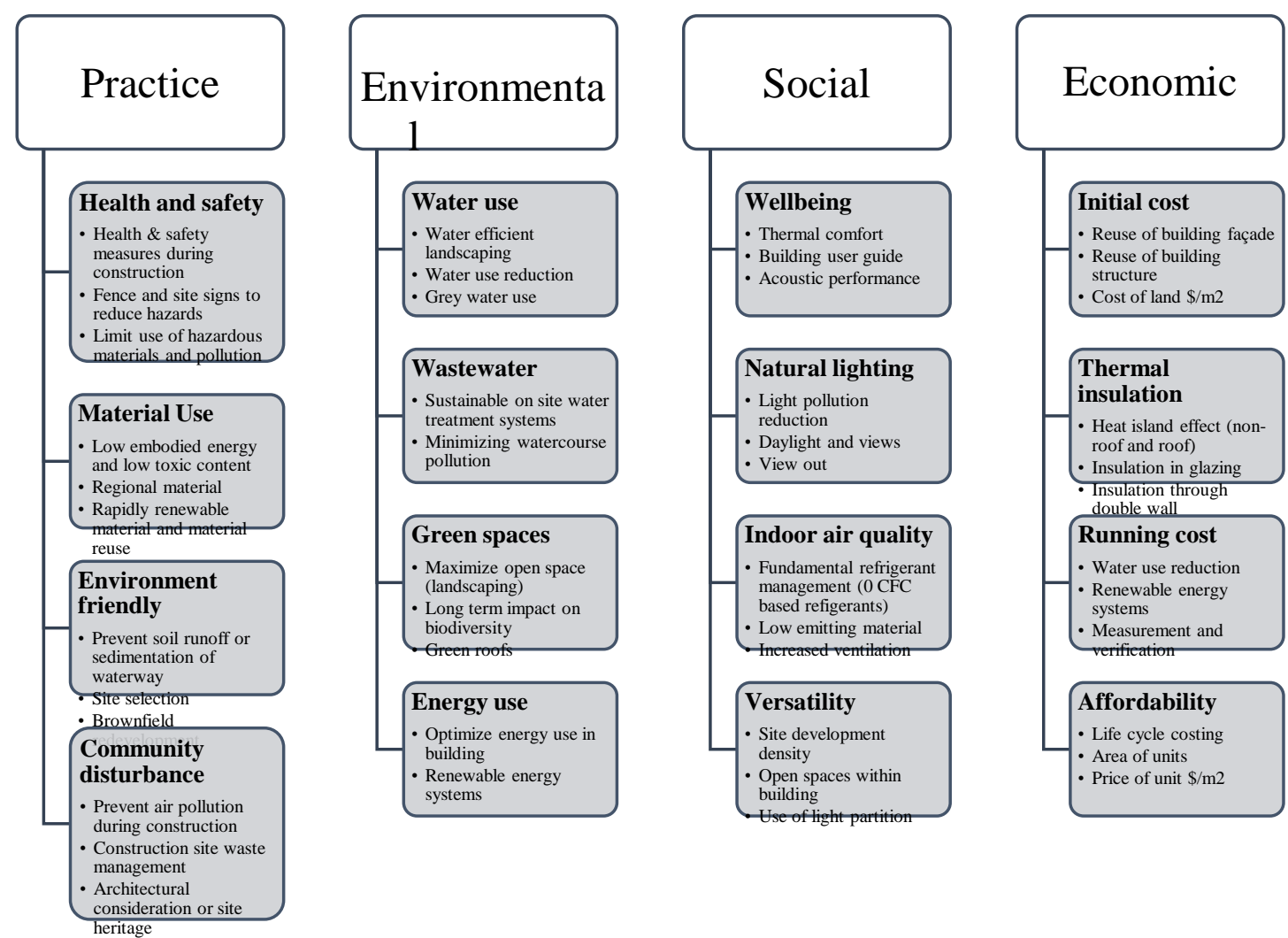

Figure 1. Description of survey questionnaire including four assessed sustainability pillars. 


\section{Development of Sustainability Index}

A popular misconception among construction stakeholders that is also supported by the most commonly used rating systems is that sustainable buildings only aim to preserve the environment. Consequently, these stakeholders lose interest in pursuing sustainable development for fear of over-investing or even implementing financial burdens that are rather dispensable. In reality, sustainable buildings should thrive to fundamentally preserve the environmental, economic and social stocks simultaneously within a proper practice during construction. Hence, this study developed a graphical sustainability index that agglomerates all the information about a building's sustainable practices and presents them graphically into four distinct quadrants that reflect the four aforementioned pillars as shown in Error! Reference source not found.. This index reciprocates the survey structure and includes all sustainability criteria evaluated in the survey. Each quadrant incorporates a set of parameters where the performance within each is evaluated based on a group of sub-parameters. For example, the practice quadrant includes four parameters: health and safety, material use, environment friendly, and community disturbance. If the health and safety parameter is to be assessed, then three sub-parameters must be considered: health and safety measures during construction, fence and site signs to reduce hazards, and limited use of hazardous materials and pollution.

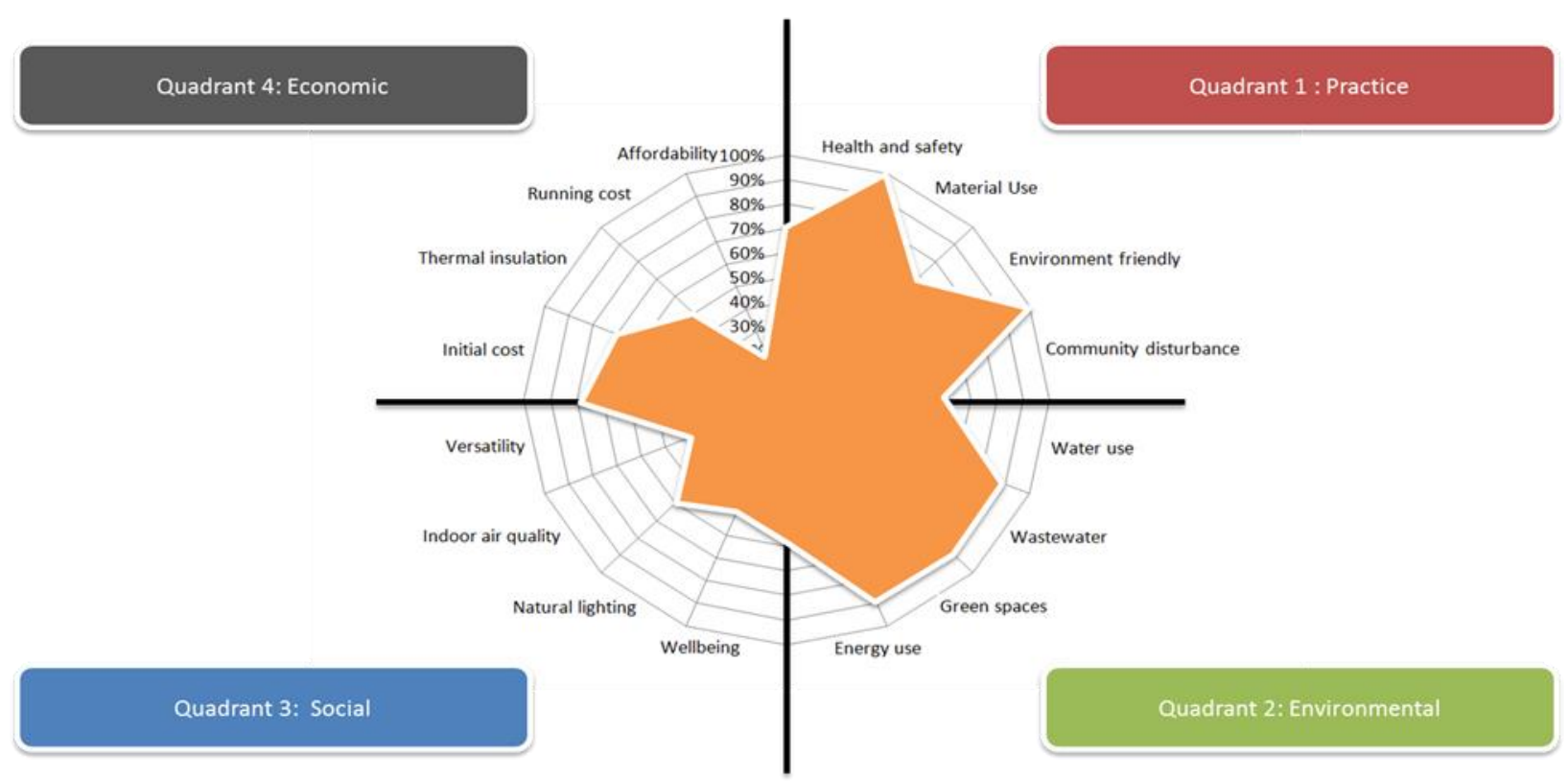

Error! Reference source not found.. Sustainability index graphical layout

The parameters within each quadrant are evaluated on a percentage scale: 
- $100 \%$ indicates a completely fulfilled requirement for the sustainability of the project's specific parameter. This implies that the project shows compliance to the parameter sustainability standards by fulfilling all the sub-parameter conditions.

- $0 \%$ indicates no compliance to a particular sustainability parameter. Such an indication implies that the project did not meet any of the subparameter conditions, and therefore does not respect the concepts of sustainable development for the evaluated feature. This is a weakness when it comes to the project's sustainability.

- Scores in between arise when a project satisfies some sub-parameters of a given feature.

Each of the four quadrants involves parameters that tend to be related and denotes a particular sustainability emphasis. When one particular quadrant is relatively more inflated than another, it can be implied that the project exhibits tradeoffs. A project classification system is described in Table 1 which indicates the followed sustainability features in a project. For example, a project is classified as IE if its graphical sustainability index shows an inflated shape in the environmental quadrant. It is most likely for a project to show more than one inflated quadrant and in this case it would have a composite classification. As an illustration, a project with high emphasis on both social and economic aspects would be classified as IS-IM.

Table 1. Classification of construction projects according to their implemented sustainability features.

\begin{tabular}{|c|c|c|}
\hline Indicator classification & Shape - Visualization & Potential Significance \\
\hline $\begin{array}{l}\text { IP } \\
\text { (Practice) }\end{array}$ & $\begin{array}{c}\text { Inflated shape in quadrant } \\
1\end{array}$ & $\begin{array}{l}\text { Project presents strong } \\
\text { sustainability in practice. } \\
\text { The contractor has } \\
\text { implemented proper } \\
\text { construction methods and } \\
\text { techniques that meet } \\
\text { sustainable development } \\
\text { requirements. }\end{array}$ \\
\hline $\begin{array}{l}\text { IE } \\
\text { (Environmental) }\end{array}$ & $\begin{array}{l}\text { Inflated shape in quadrant } \\
2\end{array}$ & $\begin{array}{l}\text { Project presents strong } \\
\text { sustainability in } \\
\text { environmental } \\
\text { considerations. Design } \\
\text { specifications account for } \\
\text { water, wastewater, green } \\
\text { spaces and energy use. }\end{array}$ \\
\hline $\begin{array}{l}\text { IS } \\
\text { (Social) }\end{array}$ & Inflated shape in quadrant & $\begin{array}{l}\text { Project presents strong } \\
\text { sustainability in social } \\
\text { considerations. Design } \\
\text { takes into account the } \\
\text { tenant's quality of life } \\
\text { including wellbeing, }\end{array}$ \\
\hline
\end{tabular}




\begin{tabular}{|l|l|l|}
\hline & & $\begin{array}{l}\text { natural lighting, and } \\
\text { versatility of use. }\end{array}$ \\
\hline $\begin{array}{l}\text { IM } \\
\text { (Economic) }\end{array}$ & $\begin{array}{l}\text { Inflated shape in quadrant } \\
4\end{array}$ & $\begin{array}{l}\text { Project presents strong } \\
\text { sustainability in economic } \\
\text { considerations such as } \\
\text { running cost, } \\
\text { affordability, and others. }\end{array}$ \\
\hline
\end{tabular}

The main objectives behind the developed graphical index which assesses the project's performance in four main sustainability pillars are to highlight the project's weaknesses and strengths over the wide range of evaluated criteria, to enable the observation of sustainability patterns, and to allow easy visualization of common sustainability tradeoffs in a construction market. This index is used in the following section to assess the surveyed sustainable projects in the Lebanese market in order to observe which features are prioritized over others and to identify sustainability patterns that are particular to this market. This serves to address the question of whether sustainability is perceived as a marketing trend or a serious commitment to the environment wellbeing in this industry.

\section{RESULTS AND DISCUSSION}

This study shows the graphical sustainability index for each project exhibiting different shapes within the four considered quadrants and consequently reflecting varying sustainable practices and emphasis as shown in Figure 3. It is observed that these projects have targeted somewhat a balanced sustainable profile shown through having the four quadrants more or less equally filled.

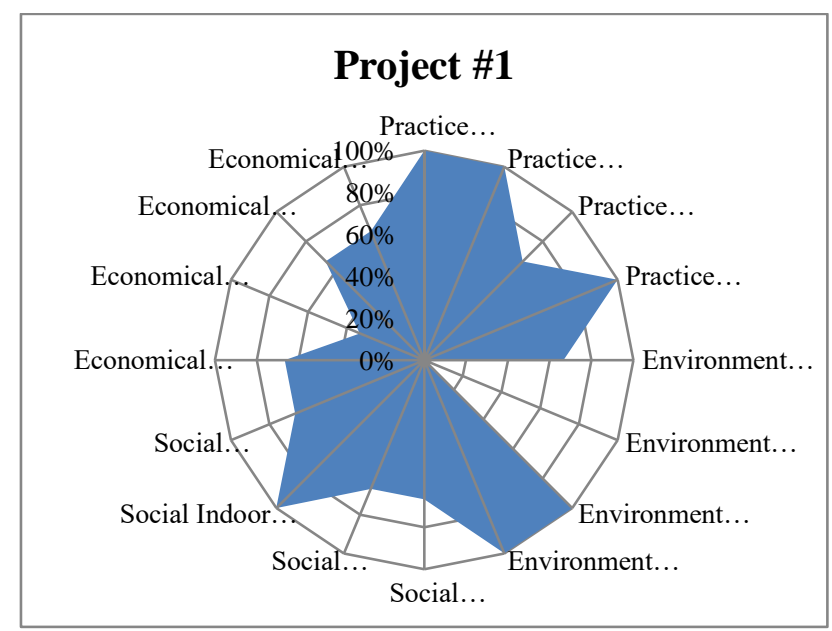




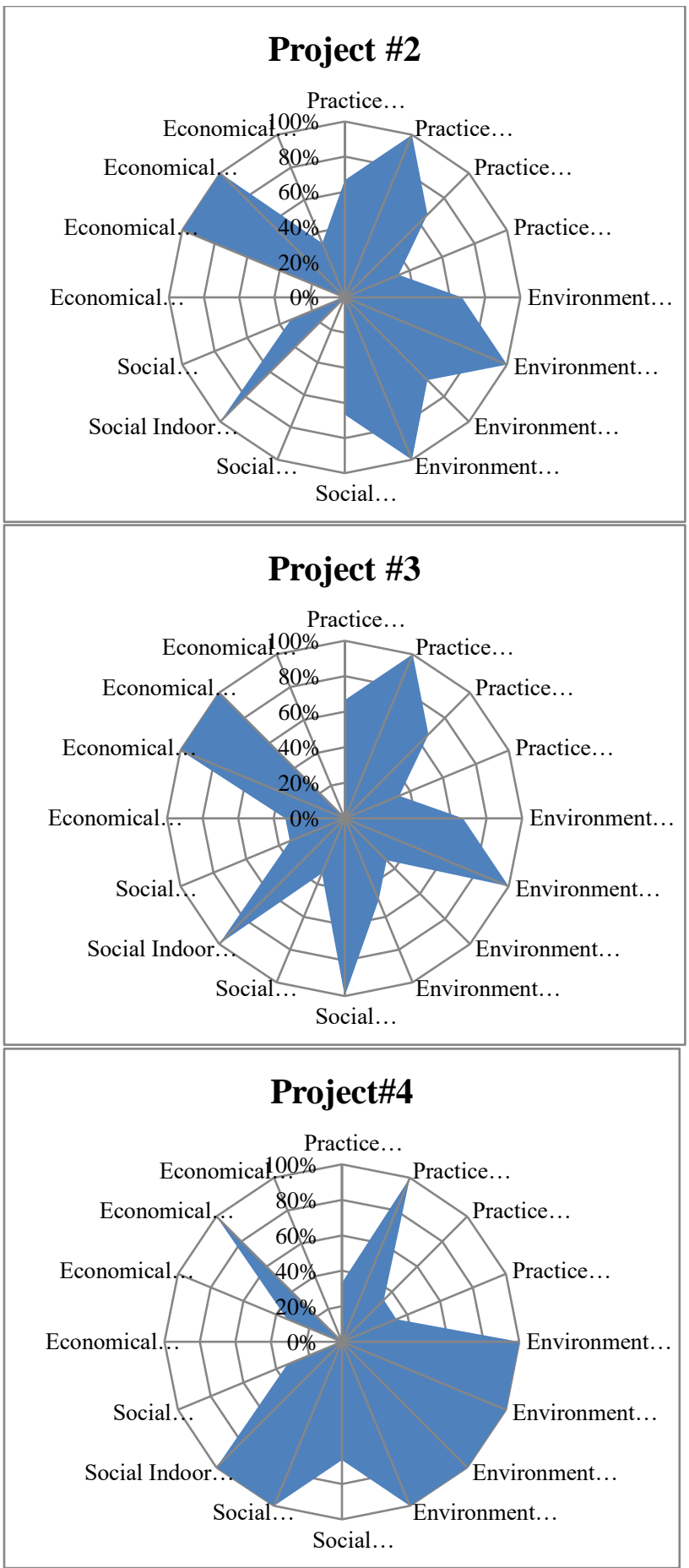

Error! Reference source not found.. Graphical index reflecting individual compliance of each surveyed project to the four sustainability pillars.

However, it is observed that projects \#1 and \#4 emphasized respectively the practice and environmental aspects at the expense of the economical one. In general, the economical pillar seem to be less emphasized than the other three pillars which again shows that the cost of going green constitutes a main disincentive for developers 
against sustainable construction. This was further affirmed through the interviewees' unified statement that the choice of sustainability measures to adopt in their projects is mainly based on the pertaining cost implications, the ease of implementation, and the market availability of required products.

Based on the interviewees' feedback and the resulting graphical sustainability index shape for the four surveyed projects, it can be concluded that despite the growing number of buildings pursuing sustainability certification systems, the entire concept of sustainable development is still at its infancy in the Lebanese market. Developers whose role is to initiate sustainable projects do not have the necessary awareness about the importance of an eco-friendly building that balances between the environmental, social and economic pillars but rather look at it as a marketing opportunity to capitalize on their investments. In fact, when asked about the motives behind adopting green features or applying for certifications, most respondents stated that going green helps increase their property value, enhance rental rates and returns, boost their reputation, and gain a competitive edge over their opponents in the market. On another note, sustainable projects are more complex to design and construct than conventional buildings and require more sophisticated skills and techniques which are scarce in the Lebanese market. This again implies higher costs and more profit uncertainty for designers and contractors. With sustainability being rather a new concept in Lebanon, the utilization of green and LEED compliant materials and technologies is still limited making their procurement cost high. Moreover, a main challenge to sustainable practice highlighted by most respondents is the cooperation of construction labor on green concepts and methodologies. Workers are used to traditional ways in construction and thus teaching them new sustainable techniques and conveying to them the importance of sustainable construction requires a great deal of patience and persistence. In addition, some of the LEED requirements are tailored to the US environment and are rather difficult to be attained in Lebanon such as public transportation and others.

\section{CONCLUSION AND RECOMMENDATIONS}

This paper aimed to shed light on the emerging concept of sustainable construction and its proper implementation in general and particularly in Lebanon. This study therefore investigated the level of commitment of Lebanese construction stakeholders to sustainable practices through observing a group of projects that have been gold certified.

Based on the analysis of surveyed projects and the collected feedback from main stakeholders, the desire to chase LEED for its status symbol rather than its actual environmental benefits prevails through the selection of easily applicable sustainable features at the least cost. Most respondents indicated that the minimum number of points required to achieve a certain certification level is sought which demonstrates the desire for the certification as a marketing tool rather than a concern for the well-being of future generations.

In a developing country such as Lebanon, developers are faced with many challenges 
which limit their interest in sustainable projects. Operating in a small market with high competition and poor economical conditions, developers as well as contractors strive to make profit and sometimes must even bear low returns to sustain their industrial operation. Thus, developers are always concerned about the cost implications of going green. To address this situation which is common in many other developing countries in the region, it is imperative for the government to take a leadership role in preparing the necessary legal infrastructure, administering the proper incentives, and monitoring the application of environmental regulations in order to enhance sustainable construction practices. The government should ensure the formation of decentralized monitoring entities and staff them properly with the required skills to make sure environmental and building regulations are respected and implemented throughout the country. Beside the lack of proper legislation system with adequate monitoring agencies, Lebanon lacks the public awareness about the importance of sustainable development and preservation of the nature's resources. Thus, a critical and promising step towards achieving sustainability is raising awareness of the public about the benefits of sustainable construction through organizing more campaigns and updating our educational curriculums to teach the new generation about the environment and the relevant regulations. In addition, the private and public sectors should both coordinate and create incentives to orient developers and users towards sustainable development such as discounts on environment-friendly materials and green construction technologies, rebates on solar panels, reduced interest on loans for green houses and others.

\section{REFERENCES}

Awwad, R., and El Khoury, K. (2012). "Assessment of Sustainable Construction in Lebanon", Proceedings of the $29^{\text {th }}$ International Symposium on Automation and Robotics in Construction, Eindhoven, Netherlands, June 26-29, 2012.

Berardi, U. (2012). "Sustainability assessment in the construction sector: Rating systems and rated buildings", Sustainable Development, 20 (6), 411-424.

CIB \& UNEP (2002). "Agenda 21 for Sustainable Construction in Developing Countries", Report No Bou/E0204, CSIR Building and Construction Technology publishers, Pretoria, South Africa.

El Asmar, J.P, and Taki, A.H. (2014). "Sustainable rehabilitation of the built environment in Lebanon", Sustainable Cities and Society, Vol. 10, 22-38.

Gibberd J. (2005). "Assessing sustainable buildings in developing countries - the sustainable building assessment tool (SBAT) and the sustainable building lifecycle (SBL)", Proceedings of World Sustainable Building Conference, Tokyo, 1605-1612.

Hediger, W. (1999). "Reconciling weak and strong sustainability", International Journal of Social Economics, 26(7/8/9), pp. 1120 - 1144. 
Holton, I. Glass, I. Price, A. (2007). "Developing a successful sector sustainability strategy: six lessons from the UK construction products industry", Corporate Social Responsibility and Environmental Management, Vol.15, No. 1, pp. $29-42$.

Hugé, J., et al. (2013). "A discourse-analytical perspective on sustainability assessment: interpreting sustainable development in practice", Sustainability Science, 8(2), 187- 198.

Kibert, C. J. (2016). "Sustainable construction: Green building design and delivery", Hoboken, NJ: Wiley.

King, A.A. and Toffel, M.W. (2007). "Self-regulatory institutions for solving environmental problems: perspectives and contributions from the management literature". In Governing the Environment: Interdisciplinary Perspectives, Delmas M, Young O (eds.), Cambridge University Press: New York.

McGraw-Hill Construction. (2006). "Green building smart market report: Design \& construction intelligence", New York.

Pitt, M., Tucker, M., Riley, M., and Longden, J., (2009). "Towards sustainable construction: promotion and best practices". Construction Innovation, Vol. 9, No. 2, p. 201.

Robichaud, L. and Anantatmula, V. (2011). "Greening Project Management Practices for Sustainable Construction." J. Manage. Eng., 10.1061/(ASCE)ME.19435479.0000030, 48-57.

Said, I., Osman, O., Shafiei, M. W. M., Razak, A. A., and Rashideh, W. M. A. (2010). "Identifying the indicators of sustainability in the construction industry", International Journal of

Organizational Innovation, Vol 2, No. 3, pp. 336-350.

Sev, A. (2009). "How can the construction industry contribute to sustainable development? A conceptual framework". Sustainable Development, Vol. 7, No. 3, pp 161 - 173, DOI: $10.1002 / \mathrm{sd} .373$.

Srour, I., Chehab, G., Awwad, E., and Chong, W. (2010). "Use of Sustainable Techniques in Lebanese Construction Industry", Second International Conference on Sustainable Construction Materials and Technologies.

World Bank (2003). "Republic of Lebanon Cost Assessment of Environmental Degradation”, Draft Report 2003. 